Journal of Advanced Research in Fluid Mechanics and Thermal Sciences

\title{
Determining of Water Saturation Using Fuzzy Logic Method in Mirah-1 Well, Central Sumatra Basin of Indonesia
}

\author{
Agus Maman Abadi ${ }^{1,}{ }^{*}$, Allen Haryanto Lukmana², Aditya Wisnugraha Sugiyarto ${ }^{1}$, Hihin Vita Amalia ${ }^{1}$ \\ Mathematics Study Programme, Universitas Negeri Yogyakarta, Jalan Colombo No. 1, Yogyakarta, 55281 Indonesia \\ Department of Petroleum Engineering, University of National Development of Yogyakarta, Jalan SWK No. 104, Condongcatur, Yogyakarta, \\ 55283 Indonesia
}

\section{ARTICLE INFO}

\section{Article history:}

Received 26 December 2019

Received in revised form 19 April 2020

Accepted 22 April 2020

Available online 5 July 2020

Keywords:

Water saturation; fuzzy logic; fuzzy c-

mean clustering

\section{ABSTRACT}

Water saturation is one important factor in determining the hydrocarbon content in a rock where the less water content in the rock affects the greater the number of hydrocarbons. The purpose of this study is to determine water saturation at various depths in drilling using fuzzy logic. Input variables used are depth, effective porosity, effective porosity of density-neutron log, total porosity, total porosity of densityneutron log. Furthermore, the fuzzy C-Mean Clustering (FCM) method is used to determine the optimal number of rules. The results showed that the prediction of water saturation with zero-order Sugeno fuzzy logic gives better accuracy compared to Mamdani fuzzy logic, BPNN, and LSTM-RNN.

Copyright @ 2020 PENERBIT AKADEMIA BARU - All rights reserved

\section{Introduction}

Petroleum is the main energy source for industry, transportation, and households in Indonesia. Based on data from [1], it is said that the energy sector contributes around $7.6 \%$ to $8 \%$ annually to Indonesia's Gross Domestic Product (GDP). Among this $8 \%, 3.3 \%$ is contributed by the petroleum mining sector. In 2014, Indonesia had around 15 oil refineries that were actively producing [2]. Indonesia has oil reserves of around 3.15 billion barrels, which is estimated to be sufficient for the next ten years [3].

Petroleum processing requires a long process from drilling to refining [4]. In the process of finding suitable oil sources, precise calculations and predictions need to be conducted. Petroleum is principally found in oil reserves stored in rock deposits in the bowels of the earth [5]. Although the formation of petroleum is not precisely known, generally petroleum is formed from marine animals and plant debris that experienced high pressure and temperature. Petroleum contains a number of mixtures of hydrocarbons, non-hydrocarbons, and organometallic compounds [6]. Hydrocarbon

\footnotetext{
* Corresponding author.

E-mail address: agusmaman@uny.ac.id
}

https://doi.org/10.37934/arfmts.73.1.4658 
compounds are the main components in petroleum because all hydrocarbon classes are present in petroleum, except for alkenes and alkynes [7].

Water saturation is one of the important factors in determining the hydrocarbon content in a rock layer where the less water content in the rocks, the greater the hydrocarbon content [8]. It is the amount of pore volume in the water-filled rocks [9]. The method for estimating the volume of hydrocarbons in ground surface formation is determined based on the vertical and horizontal resistivity values. These values are determined based on the saturation of bound water, total porosity for each layer, and the estimated volume of bulk water that cannot be reduced in each layer [10]. Therefore, to determine the volume of hydrocarbons contained in the soil layer, it is necessary to conduct a prediction process of the water saturation in the layer.

At present, there is a method called machine learning, which is a collection of methods that allow computers for automatization of modeling and programming, supported by data through systematic discovery and statistically significant patterns in available data [11]. Prediction of water saturation has been carried out by utilizing several machine learning methods such as using robust committee machine and neural networks. Kenari and Mashohor have developed method to predict water saturation using several types of machine learning [12]. Alrumah and Ertekin [13] have established an artificial neural network to predict water saturation around vertical and horizontal wells. Numerical models are used to produce training data used in neural networks. Prediction of water saturation around vertical and horizontal wells uses artificial neural networks. The results showed that the reservoir model based on artificial neural networks can be used in choosing the optimal perforation interval so that it can enhance oil-free water production by delaying water production. Mohamed et al., [14] have predicted 3D high resolution water saturation using a combination of geostatistical inversion and neural network analysis. The results showed that the proposed method has provided high accuracy in predicting water saturation compared to the previous method. Mardi et al., [15] have used artificial neural network and Archie's equation's components with the various cementation factor and saturation exponent to get the highest accuracy in predicting of water saturation. Hamada et al., [16] have applied the artificial neural network with two hidden layers and one output layer to estimate the water saturation of shaly sandstone reservoirs. Wood has applied the transparent open box (TOB) learning network to estimate water saturation [17]. Zhang et al., [18] have proposed the machine learning methods to predict water saturation. In addition, the prediction of water saturation has also been done by equation modeling [19]. Fuzzy system is one of the techniques of soft computing and part of artificial intelligence with machine learning [20-22]. Mamdani fuzzy logic has been applied to predict hydrocarbon prospective zone [23]. Hereafter, fuzzy control has been used in wastewater treatment systems by applying fuzzy logic to control undesirable bacteria that automatically checking temperature, $\mathrm{pH}$, and water level. Furthermore, this system has been implemented with a computer and Smartphone [24].

The advantage of neural network model is that the modeling process does not require assumptions in the data that are often difficult to fulfill. However, the weakness of this model is that the process is not transparent in a black box. While the advantage of fuzzy modeling is being able to model data based on a combination of empirical data and expert knowledge in the form of fuzzy logic. The transparency process in fuzzy modeling can be seen from the fuzzy logic used in modeling. The purpose of this study is to determine water saturation at various depths in drilling using a fuzzy system. In this study, the prediction process of water saturation is based on the variables of depth, effective porosity, effective porosity of density-neutron log, total porosity, and total porosity of density-neutron log. Fuzzy rule formation uses fuzzy c-means clustering (FCM) and zero-order Sugeno fuzzy logic. The FCM method is used to determine the most optimal number of rules used in the 
formation of fuzzy rules. Furthermore, the kind of fuzzy rules of the fuzzy system is the zero-order Sugeno.

\section{Theoretical Review}

\subsection{Water Saturation}

All petroleum, whichever its origin has a main component which is hydrocarbons mixture. The mixture of hydrocarbons contained in the petroleum has several variations, namely sulfur compounds, nitrogen, and oxygen [25]. Hydrocarbon saturation can be determined by water saturation, which is 1 minus the value of water saturation. Water saturation is the ratio of water volume to pore volume. In a water-wet reservoir, water is held by surface tension and surface water does not move when oil or gas is produced. This situation can be shown by Figure 1.

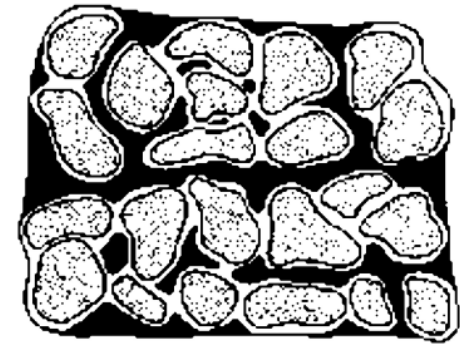

(a)

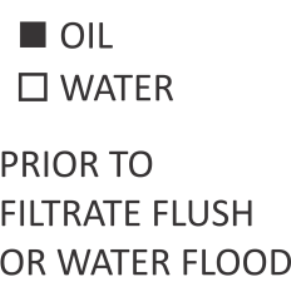

Fig. 1. Water-wet formation with hydrocarbons [26]; (a)

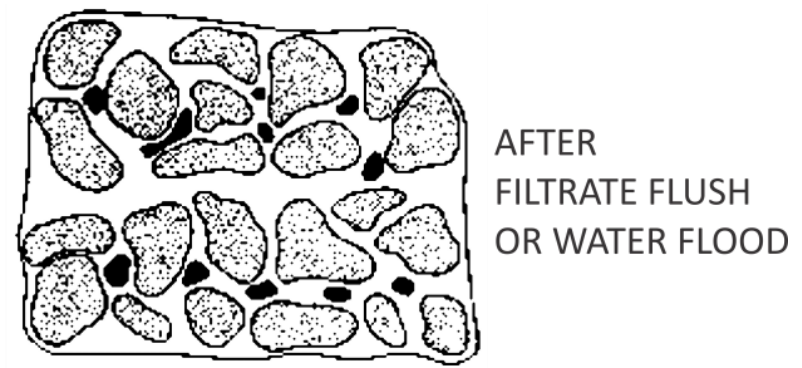

(b)

When the reservoir is drilled, fluids near the wellbore are pushed away and the zone is attacked by the drilling fluid. If hydrocarbons exist, the value of water saturation after the invasion will be higher than the original reservoir conditions. Shallow log resistivity will indicate the water saturation of the invasion zone whereas the deep resistivity log will indicate the water saturation of the original formation if only the invasion is not too deep.

Almost all water saturation calculations are carried out by using the Archie's Laws approach in which the depth resistivity, porosity, water resistivity, and electronic property variables are used. However, in the calculation, water saturation can be calculated from the effective porosity and resistivity log [26]. Since porosity is the capacity of a rock to hold a liquid, it can be used to calculate water saturation that occurs.

\subsection{Fuzzy Logic of Zero-Order Sugeno}

There are several types of fuzzy logic such as Mamdani, Sugeno, and Tsukamoto. In this study, zero-order Sugeno fuzzy logic is used. Sugeno fuzzy logic model, also known as Takagi-Sugeno-Kang (TSK) fuzzy logic model, is a systematic approach to produce fuzzy rules from the applied input-output data $[27,28]$. Zero-order Sugeno fuzzy logic is stated in the following formula.

If $x_{1}$ is $A_{1}, \ldots$, and $x_{n}$ is $A_{n}$, then $z=b$

where $\left(x_{1}, \ldots, x_{n}\right)$ is the input of fuzzy logic, $A_{i}$ is the fuzzy set on the $\mathrm{i}^{\text {th }}$ input, and consequent $b$ is a real constant. 


\subsection{Fuzzy C-Means Clustering}

Fuzzy clustering is a powerful non-supervised method for data analysis and model construction. In many situations, fuzzy clustering is more natural than hard clustering. The data that are located on the boundary between several classes are not forced to be part of one class but the data are rather represented in a degree of membership, indicating the partial membership of the data. Fuzzy cmeans (FCM) algorithm is the most widely used. This algorithm was first declared in the special cases $(m=2)$ by Joe Dunn in 1974. For general case, it was constructed by Jim Bezdek in his Ph.D. thesis at Cornell University in 1973. The algorithm was then improved by Bezdek in 1981 [29]. The FCM method uses fuzzy partitions so that data points can include to all groups with varying membership values in the interval [0 1] with the following steps [29].

i. The initialization of matrix $U=\left[u_{i j}\right], U^{0}$

ii. In the $k^{\text {th }}$ step calculate the center of vector $C^{(k)}=\left[c_{j}\right]$ with $U^{k}$

$$
C_{i}=\frac{\sum_{j=1}^{n} u_{i j}^{m} x_{j}}{\sum_{j=1}^{n} u_{i j}^{m}}
$$

iii. Update $U^{k}, U^{(k+1)}$

iv. $\quad d_{i j}=\sqrt{\sum_{i=1}^{n}\left(x_{i}-c_{i}\right)}$

$$
\text { a. } u_{i j}=\frac{1}{\sum_{k=1}^{c}\left(\frac{d_{i j}}{d_{k j}}\right)^{\frac{2}{m-1}}}
$$

v. If $|U(k+1)-U(k)|<\varepsilon$ then, stop. If not, then return to step 2 .

where $m$ is a random real number greater than $1, u_{i j}$ is the degree of membership of $x_{i}$ in cluster $j, x_{i}$ is the measurement of the $i^{\text {th }} d$-dimension, and $c_{j}$ is the center of the $d$-dimension of the cluster.

\section{Research Method}

In this study, the data were taken from the Mirah-1 well, Pematang Group Metas Field in the central Sumatra basin of Indonesia conducted by PT. Geotama Energi, Yogyakarta, Indonesia. This company is a service-oriented business providing specialized oilfield general equipment, mechanical electrical, and engineering that was established since 2006. This study used 2252 data taken with varying depths from 1393 meters to 1721 meters. Hereafter, the data were divided into 75\% for training data and $25 \%$ for testing data. Furthermore, the input variables used in this study are depth, effective porosity, effective porosity of density-neutron log, total porosity, and total porosity of density-neutron log. The output variable of the fuzzy system is water saturation. The next step was the clustering process using FCM, which was followed by the fuzzification and processing of the fuzzification results data using the zero-order Sugeno fuzzy system. The accuracy of the predicted results is measured by the mean absolute percentage error (MAPE) value as in Eq. (2) [30].

$M A P E=\frac{\sum_{i=1}^{n} \frac{\left|X_{i}-F_{i}\right|}{X_{i}} x 100 \%}{n}$

where $X_{\mathrm{i}}$ is the original data, $F_{\mathrm{i}}$ is predictive data, and $n$ is the amount of data. The determination of the model accuracy is measured separately based on the type of data, so two MAPE values were obtained, namely for training data and testing data. In general, the research flow diagram can be seen in Figure 2. 


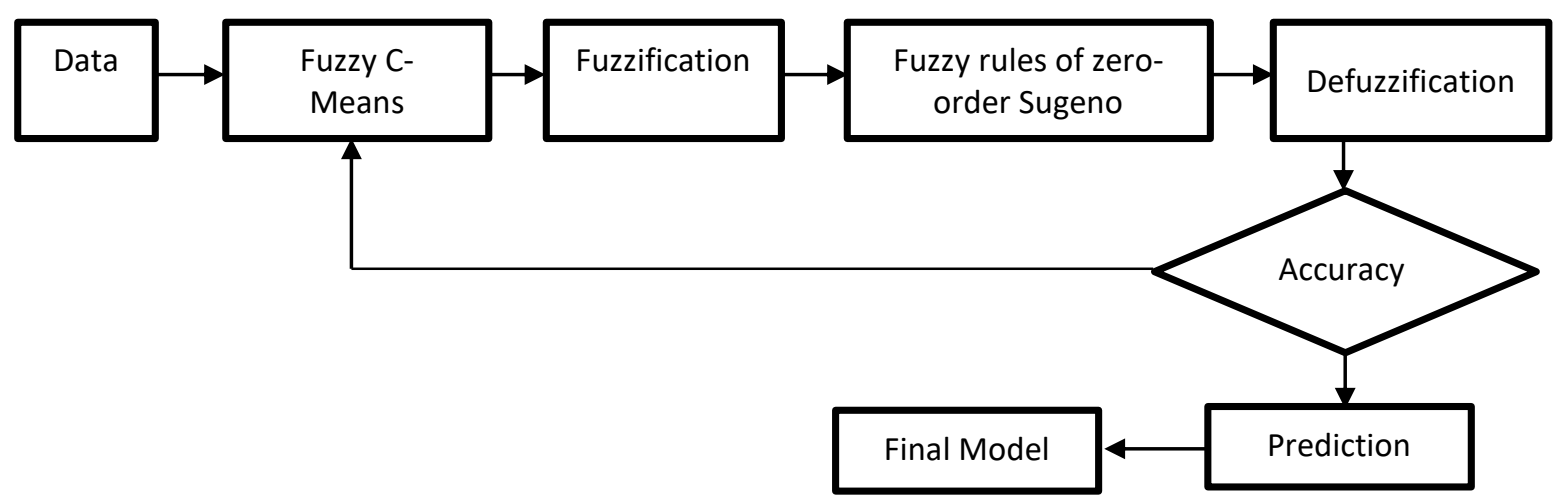

Fig. 2. Research Flow Chart

\section{Result and Discussion}

\subsection{Fuzzy C-Means Clustering}

The determination of the optimal cluster as Eq. (1) is conducted through a try and error method to get the lowest MAPE value for training and testing data. The results are illustrated in Table 1.

Table 1

The results of the try and error method

\begin{tabular}{llll}
\hline Cluster Number & $\begin{array}{l}\text { MAPE (\%) } \\
\text { Training }\end{array}$ & Testing & $\begin{array}{l}\text { Mean MAPE } \\
(\%)\end{array}$ \\
\hline 10 & 28.71424 & 29.12068 & 28.91746 \\
11 & 28.94677 & 28.84113 & 28.89395 \\
12 & 27.48908 & 27.6391 & 27.56409 \\
.. & $\ldots$ & $\ldots$ & $\ldots$ \\
150 & 15.55787 & 15.26276 & 15.41031 \\
151 & 14.16582 & 13.64534 & 13.90558 \\
152 & 14.22539 & 14.17532 & 14.20036 \\
$\ldots$ & $\ldots$ & $\ldots$ & $\ldots$ \\
481 & 10.98571 & 10.83086 & 10.90829 \\
482 & 10.72528 & 10.53904 & 10.63216 \\
483 & 10.93887 & 10.49228 & 10.71557 \\
484 & 9.939734 & 9.343554 & 9.641644 \\
\hline
\end{tabular}

Based on Table 1, it is found that the lowest MAPE value was achieved in the 484th cluster so that the center matrix of $484 \times 6$ was obtained. After that, the obtained center was then used to create a zero-order Sugeno fuzzy rules with 484 fuzzy rules. The obtained center matrix can be seen in Table 2.

Table 2

The center of optimal cluster

\begin{tabular}{lllllll}
\hline Cluster & Depth & PHIE & PHIE_DN & PHIT & PHIT_DN & SWE \\
\hline 1 & 1570.634471 & 0.157510931 & 0.157511004 & 0.157511554 & 0.157511627 & 0.20790815 \\
2 & 1665.302142 & 0.175397492 & 0.175398214 & 0.17540327 & 0.175403992 & 0.176808947 \\
3 & 1456.999665 & 0.200987456 & 0.20098793 & 0.201035045 & 0.201035518 & 0.189031043 \\
$\ldots$ & $\ldots$ & $\ldots$ & $\ldots$ & $\ldots$ & $\ldots$ & $\ldots$ \\
$\ldots$ & $\ldots$ & $\ldots$ & $\ldots$ & $\ldots$ & $\ldots$ & $\ldots$ \\
484 & 1465.251391 & 0.212678851 & 0.212679213 & 0.212692605 & 0.212692967 & 0.18424892 \\
\hline
\end{tabular}




\subsection{Construction of Zero-order Sugeno Fuzzy Logic}

The process to determine water saturation using zero-order Sugeno fuzzy logic was carried out with the following steps:

\subsubsection{Fuzzy set formation for each input variable}

a) Variable of Depth

Based on the data, the depth variable has a minimum value of 1393.393 and a maximum value of 1720.748. Therefore, the universal set of this variable is $U_{\text {depth }}=[1393.393,1720.748]$. After that, the 484 fuzzy sets are defined based on the centers that have been obtained from FCM, namely $D E P_{1}, D E P_{2}, D E P_{3}, \ldots, D E P_{484}$ with the membership functions as follows.

$$
\begin{aligned}
& \mu_{D E P_{1}}(x)=e^{-\frac{(x-1570.634471)^{2}}{2(17.38)^{2}}} \\
& \mu_{D E P_{2}}(x)=e^{-\frac{(x-1665.302142)^{2}}{2(17.38)^{2}}} \\
& \mu_{D E P_{3}}(x)=e^{-\frac{(x-1457)^{2}}{2(17.38)^{2}}} \\
& \ldots \\
& \mu_{D E P_{484}}(x)=e^{-\frac{(x-1465.251391)^{2}}{2(17.38)^{2}}}
\end{aligned}
$$

The membership functions of the fuzzy sets are presented in Figure 3.

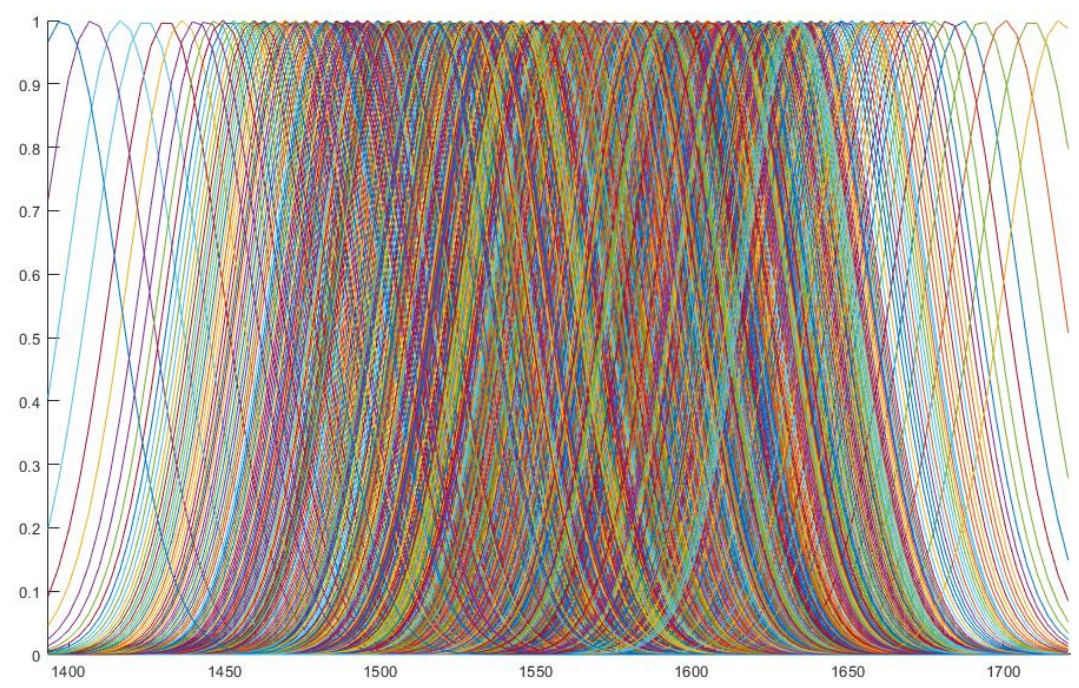

Fig. 3. Membership Function of fuzzy sets in the variable of depth

b) Variable of Effective Porosity (PHIE)

Based on the data, the effective porosity variable has a minimum value of 0 and a maximum value of 0.3. Therefore, the universal set of this variable is $U_{P H I E}=[0,0.3]$. After that, the 484 fuzzy sets are defined based on the centers that have been obtained from FCM, which are $P_{H I E_{1}}, \mathrm{PHIE}_{2}, \mathrm{PHIE}_{3}, \ldots, \mathrm{PHIE}_{484}$ with the membership functions as follows. 


$$
\begin{aligned}
& \mu_{\text {PHIE }_{1}}(x)=e^{-\frac{(x-0.157510931)^{2}}{2(0.01593)^{2}}} \\
& \mu_{\text {PHIE }_{2}}(x)=e^{-\frac{(x-0.175397492)^{2}}{2(0.01593)^{2}}} \\
& \mu_{\text {PHIE }_{3}}(x)=e^{-\frac{(x-0.200987456)^{2}}{2(0.01593)^{2}}}
\end{aligned}
$$

$\mu_{P H I E_{484}}(x)=e^{-\frac{(x-0.212678851)^{2}}{2(0.01593)^{2}}}$

The membership functions of the fuzzy sets are presented in Figure 4.

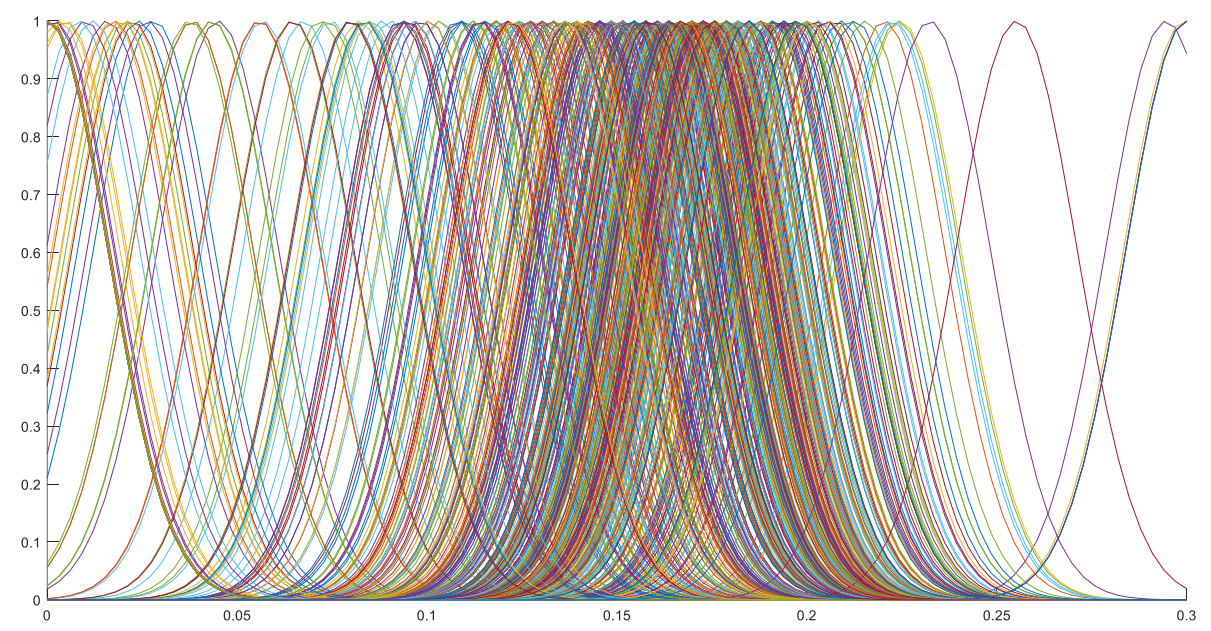

Fig. 4. Membership Function of fuzzy sets in PHIE variable

c) Variable of Effective Porosity of Density-Neutron Log (PHIE_DN)

Based on the data, the minimum and maximum values of the effective porosity of densityneutron log variable are -0.0021 and 0.467655 , respectively, and so the universal set for this variable is $U_{P H I E_{-} D N}=[-0.0021,0.467655]$. After that, the 484 fuzzy sets are defined based on the centers that have been obtained from $\mathrm{FCM}$, namely $P H I E_{-} D N_{1}, P H I E_{-} D N_{2}, P H I E_{-} D N_{3}$, ..., PHIE_DN ${ }_{484}$ with the membership functions as follows.

$$
\begin{aligned}
& \mu_{P_{H I E_{-} D N_{1}}}(x)=e^{-\frac{(x-0.157511004)^{2}}{2(0.02462)^{2}}} \\
& \mu_{\text {PHIE_DN }_{2}}(x)=e^{-\frac{(x-0.175398214)^{2}}{2(0.02462)^{2}}} \\
& \mu_{\text {PHIE_DN }_{3}}(x)=e^{-\frac{(x-0.20098793)^{2}}{2(0.02462)^{2}}} \\
& \mu_{\text {PHIE_DN484 }_{\text {D }}}(x)=e^{-\frac{(x-0.212679213)^{2}}{2(0.02462)^{2}}}
\end{aligned}
$$

The membership functions of the fuzzy sets are presented in Figure 5. 


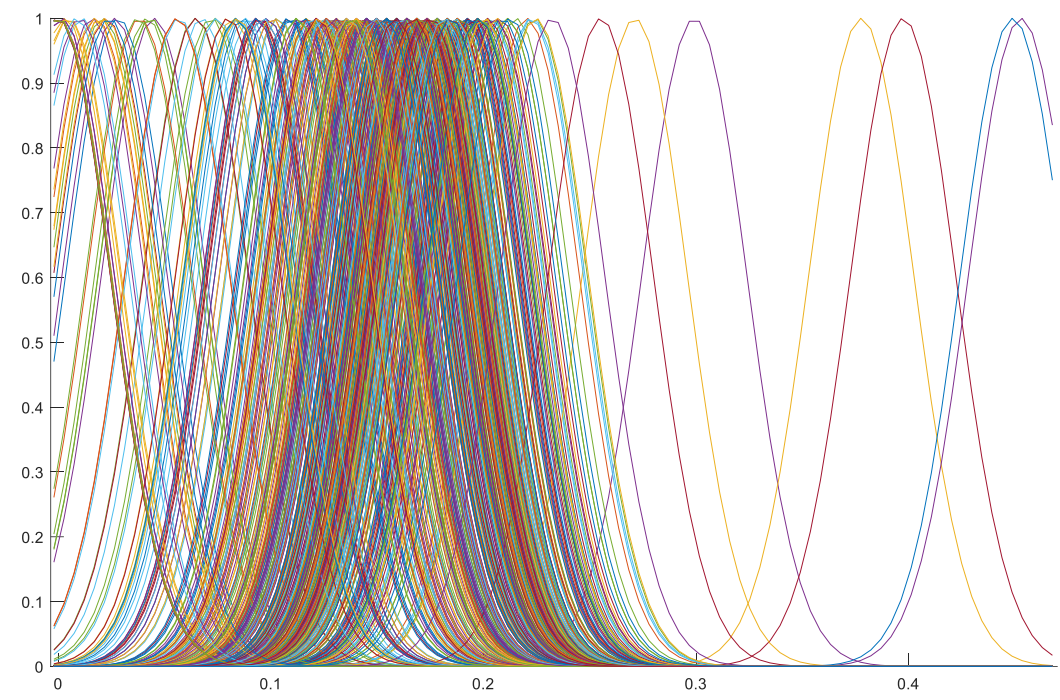

Fig. 5. Membership Function of fuzzy sets in PHIE_DN variable

d) Variable of Total Porosity (PHIT)

Based on the data, the minimum and maximum values of the total porosity are 0.077538 and 0.3 , respectively, therefore the universal set of this variable is $U_{P H I T}=[0.077538,0.3]$. Thereafter, the 484 fuzzy sets are defined based on the centers that have been obtained from FCM, namely PHIT $_{1}$, PHIT $_{2}$, PHIT $_{3}, \ldots$, PHIT $_{484}$ with the membership functions as follows.

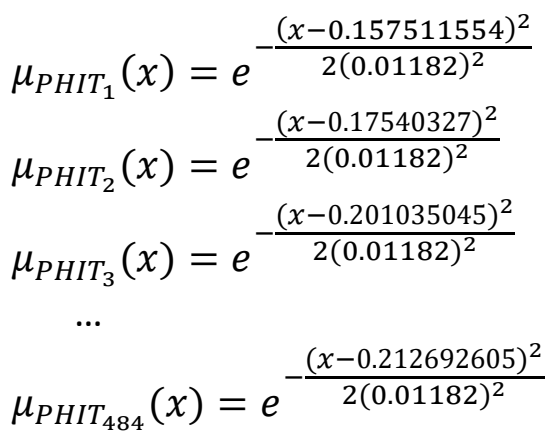

The membership functions of the fuzzy sets are presented in Figure 6.

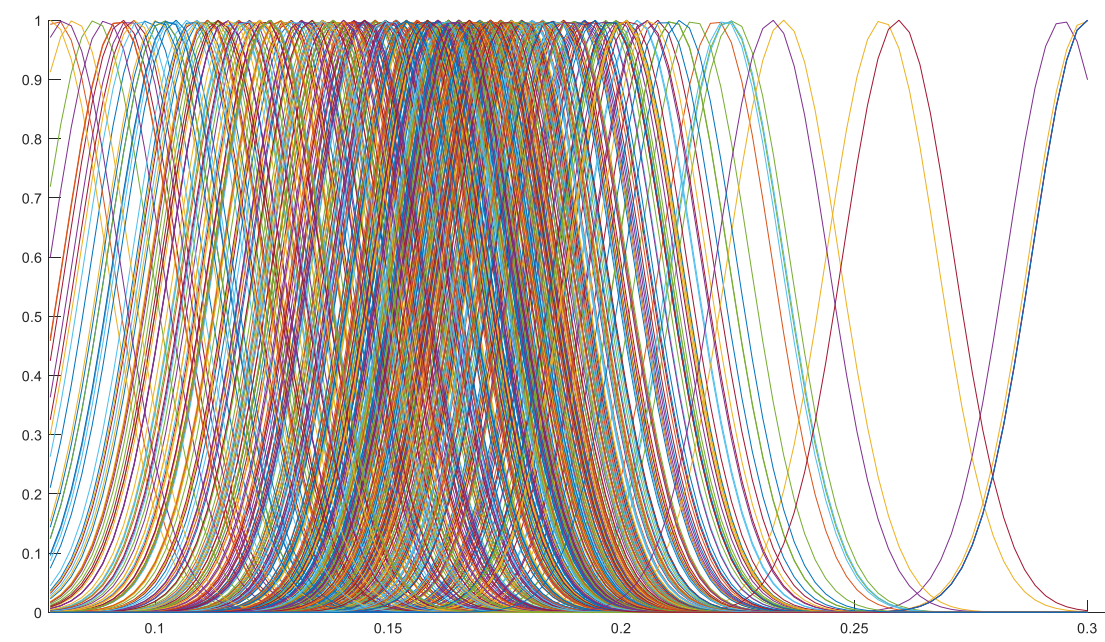

Fig. 6. Membership Function of fuzzy sets in PHIT variable 
e) Variable of Total Porosity of Density-Neutron Log (PHIT_DN)

Based on the data, the minimum and maximum values of the total porosity of density-neutron log variable are 0.077538 and 0.467655 , consecutively. Therefore, the universal set of this variable is $U_{P H I T \_D N}=[0.077538,0.467655]$. After that, the 484 fuzzy sets are defined, which are PHIT_DN, PHIT_DN, PHIT_DN $3, \ldots, P H I T \_D N_{484}$ with the membership functions as follows.

$\mu_{\text {PHIT_DN }_{1}}(x)=e^{-\frac{(x-0.157511627)^{2}}{2(0.0204)^{2}}}$
$\mu_{\text {PHIT_DN }_{2}}(x)=e^{-\frac{(x-0.175403992)^{2}}{2(0.0204)^{2}}}$
$\mu_{\text {PHIT_DN }_{3}}(x)=e^{-\frac{(x-0.201035518)^{2}}{2(0.0204)^{2}}}$
$\quad \ldots$
$\mu_{\text {PHIT_DN484 }_{2}}(x)=e^{-\frac{(x-0.212692967)^{2}}{2(0.0204)^{2}}}$

The membership functions of the fuzzy sets are presented in Figure 7.

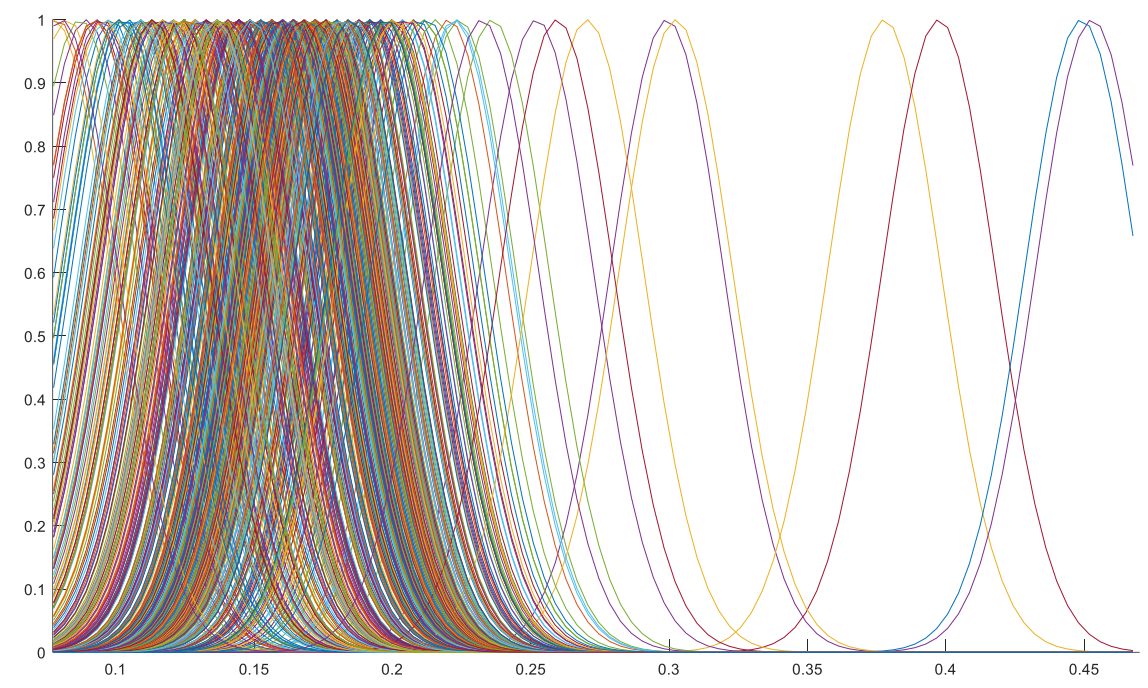

Fig. 7. Membership Function of fuzzy sets in PHIT_DN variable

\subsubsection{The determination of fuzzy rules}

Based on Table 1, 484 optimal clusters are obtained and therefore there are 484 zero-order Sugeno fuzzy rules which can be stated as follows:

Rule (1) "IF $x_{1}=$ DEP $_{1}$ and $x_{2}=$ PHIE $_{1}$ and $x_{3}=$ PHIE_DN 1 and $x_{4}=$ PHIT $_{1}$ and $x_{5}=$ PHIT_DN 1, THEN $y=$ $\mathrm{b}_{1}{ }^{\prime \prime}$

Rule (2) "IF $x_{1}=$ DEP $_{2}$ and $x_{2}=$ PHIE $_{2}$ and $x_{3}=$ PHIE_DN 2 and $x_{4}=$ PHIT $_{2}$ and $x_{5}=$ PHIT_DN 2, THEN $y=$ $\mathrm{b}_{2}{ }^{\prime \prime}$

Rule (3) "IF $x_{1}=$ DEP $_{3}$ and $x_{2}=$ PHIE $_{3}$ and $x_{3}=$ PHIE_DN ${ }_{3}$ and $x_{4}=$ PHIT $_{3}$ and $x_{5}=$ PHIT_DN ${ }_{3}$, THEN $y=$ $\mathrm{b}_{3}{ }^{\prime \prime}$ 
Rule (484) "IF $x_{1}=D_{48}$ and $x_{2}=P_{4 H I E} 484$ and $x_{3}=$ PHIE_DN 484 and $x_{4}=$ PHIT 484 and $x_{5}=$ PHIT_DN 484 , THEN $y=b_{484}$ "

where $b$ is the value of the 6th column in the matrix center presented in Table 2.

\subsubsection{Defuzzification}

Furthermore, the defuzzification, which is a process of changing a fuzzy set into a real number [31], was carried out. In this study, the weight average is used in the defuzzification process using the Eq. (3) [32].

$y=\frac{\sum_{i=1}^{484} y_{i}\left(\mu_{A_{i 1}}\left(x_{1}\right) \mu_{A_{i 2}}\left(x_{2}\right) \ldots \mu_{A_{i n}}\left(x_{n}\right)\right)}{\sum_{i=1}^{484}\left(\mu_{A_{i 1}}\left(x_{1}\right) \mu_{A_{i 2}}\left(x_{2}\right) \ldots \mu_{A_{i n}}\left(x_{n}\right)\right.}$

where $\mu_{A_{i j}}$ is a membership function of fuzzy set of the $j^{\text {th }}$ input and $i^{\text {th }}$ rule, and $y_{i}$ is a consequent part of the $i^{\text {th }}$ rule.

\subsection{Model Testing}

Model testing was carried out by comparing the MAPE values of each model using Eq. (2). The model that has the smallest MAPE will be used as the final model. In this study, the smallest obtained value of MAPE for training data and testing data are:

$M A P E_{\text {Training }}=\frac{\sum_{i=1}^{1689} \frac{\left|X_{i}-F_{i}\right|}{X_{i}} \times 100 \%}{1689}=9.9397 \%$

$M A P E_{\text {Testing }}=\frac{\sum_{i=1}^{563} \frac{\left|X_{i}-F_{i}\right|}{X_{i}} \times 100 \%}{563}=9.3436 \%$

Furthermore, the prediction of water saturation by using several other methods was also performed such as Mamdani fuzzy logic, Back-Propagation Neural Network (BPNN), and Long Short Term Memory Recurrent Neural Network (LSTM-RNN). A comparison of the results of prediction accuracy with various methods can be seen in Table 3 .

Table 3

The comparison of prediction using several methods

\begin{tabular}{lll}
\hline Method & MAPE (\%) & \\
& Training & Testing \\
\hline Zero-order Sugeno fuzzy logic & 9.9397 & 9.3436 \\
Mamdani fuzzy logic & 17.0139 & 16.3307 \\
BPNN & 10.9144 & 10.2579 \\
LSTM-RNN & 41.5080 & 36.6248 \\
\hline
\end{tabular}

Based on Table 3, prediction accuracy with the zero-order Sugeno fuzzy method gives better results compared to other methods, with MAPE values for training and testing data $9.9397 \%$ and $9.3436 \%$, respectively. Moreover, the BPNN method provides better prediction accuracy compared 
to the Mamdani fuzzy logic and the LSTM-RNN methods. While, the prediction of water saturation using Mamdani fuzzy logic gives better results than LSTM-RNN method.

\section{Conclusions}

In this research, the prediction of water saturation was done. The FCM method was used to reduce the number of rules in the zero-order Sugeno fuzzy model. The results of this study indicate that the prediction of water saturation using the zero-order Sugeno fuzzy method provides accuracy for training and testing data which are $90.0603 \%$ and $90.6564 \%$, respectively. These prediction results are much better compared to the Mamdani fuzzy model, BPNN, and LSTM-RNN. This shows that the zero-order Sugeno fuzzy model has advantages for the prediction of water saturation compared to other methods. In the previous study, prediction of water saturation has been carried out using several methods including composite well logs, geostatistical inversion, modelled equations, nearest-neighbor, data mining network, machine learning and neural network. Whereas, in this study, it was used the zero-order Sugeno fuzzy method. This method not only provides more accurate prediction results but also provides a transparent water saturation prediction process described through fuzzy rules. The results of this study will be used for future research development, namely, the prediction of hydrocarbon content in various layers of soil and rock using fuzzy model of first-order Sugeno.

\section{Acknowledgement}

We would like to thank PT. Geotama Energi, Yogyakarta, Indonesia for the supporting data of water saturation.

\section{References}

[1] Badan Pusat Statistika Indonesia. "Produk Domestik Bruto Indonesia Triwulanan 2015-2019." Badan Pusat Statistik (2019): 65-68.

[2] detikFinance. Ini Dia Daftar Kilang Minyak Milik Indonesia. detikfinance, May 8, 2014. https://finance.detik.com/energi/d-2576861/ini-dia-daftar-kilang-minyak-milik-indonesia.

[3] Arvirianty, Anastasia. "Cadangan Minyak RI Turun: Sisa 10 Tahun Lagi." CNBC Indonesia, January 16, 2019. https://www.cnbcindonesia.com/news/20190116111811-4-50891/waduh-cadangan-minyak-ri-turun-sisa-10tahun-lagi.

[4] Speight, James G. An Introduction To Petroleum Technology, Economics, And Politics. John Wiley \& Sons, 2011. https://doi.org/10.1002/9781118192528

[5] Younes, Mohamed Abdel-Aziz. Crude Oil Exploration in the World. InTech: Rijeka, Croatia, 2012. https://doi.org/10.5772/2676

[6] Han, Yehua, Yanfen Zhang, Chunming Xu, and Chang Samuel Hsu. "Molecular characterization of sulfur-containing compounds in petroleum." Fuel 221 (2018): 144-158.

https://doi.org/10.1016/j.fuel.2018.02.110

[7] Bayona, Josep M., Carmen Domínguez, and Joan Albaigés. "Analytical developments for oil spill fingerprinting." Trends in Environmental Analytical Chemistry 5 (2015): 26-34.

https://doi.org/10.1016/j.teac.2015.01.004

[8] Goodwin, Anthony RH, Laurent Pirolli, Eric F. May, and Kenneth N. Marsh. "Conventional Oil and Gas." In Future Energy, pp. 19-52. Elsevier, 2014.

https://doi.org/10.1016/B978-0-08-099424-6.00002-8

[9] Lyons, William. Working guide to reservoir engineering. Gulf professional publishing, 2009.

[10] Afizu, Mamudu. "Determining the relationship between resistivity, water and hydrocarbon saturation of rock formation using composite well logs." Academic Journal of Interdisciplinary Studies 2, no. 13 (2013): 119-123. https://doi.org/10.5901/ajis.2013.v2n13p119

[11] Bhavsar, Parth, Ilya Safro, Nidhal Bouaynaya, Robi Polikar, and Dimah Dera. "Machine Learning in Transportation Data Analytics." Data Analytics for Intelligent Transportation Systems (2017): 283-307.

https://doi.org/10.1016/B978-0-12-809715-1.00012-2 
[12] Kenari, Seyed Ali Jafari, and Syamsiah Mashohor. "Robust committee machine for water saturation prediction." Journal of Petroleum Science and Engineering 104 (2013): 1-10.

https://doi.org/10.1016/i.petrol.2013.03.009

[13] Alrumah Muhammad and Ertekin Turgay, "Prediction of the Water Saturation around Wells with Bottom Water Drive Using Artificial Neural Networks." Journal of Petroleum and Gas Engineering 10, no. 2 (2019): 14-22. https://doi.org/10.5897/JPGE2018.0299

[14] Mohamed, Islam A., Mahmoud Hemdan, Ahmed Hosny, and Mohamed Rashidy. "High-resolution water-saturation prediction using geostatistical inversion and neural network methods." Interpretation 7, no. 2 (2019): 455-465. https://doi.org/10.1190/INT-2018-0153.1

[15] Mardi, M., H. Nurozi, and S. Edalatkhah. "A water saturation prediction using artificial neural networks and an investigation on cementation factors and saturation exponent variations in an Iranian oil well." Petroleum Science and Technology 30, no. 4 (2012): 425-434. https://doi.org/10.1080/10916460903452033

[16] Gharib, H., A. Elsakka, and N. Chaw. "Artificial neural network (ANN) prediction of porosity and water saturation of shaly sandstone reservoirs." Advances in Applied Science Research 9 (2018): 26-31.

[17] Wood, David A. "Predicting porosity, permeability and water saturation applying an optimized nearest-neighbour, machine-learning and data-mining network of well-log data." Journal of Petroleum Science and Engineering 184 (2020): 1-17. https://doi.org/10.1016/i.petrol.2019.106587

[18] Zhang, Qitao, Chenji Wei, Yuhe Wang, Shuyi Du, Yuanchun Zhou, and Hongqing Song. "Potential for Prediction of Water Saturation Distribution in Reservoirs Utilizing Machine Learning Methods." Energies 12, no. 19 (2019): 1-21. https://doi.org/10.3390/en12193597

[19] Sam-Marcus, Jethro, Efeoghene Enaworu, Oluwatosin J. Rotimi, and Ifeanyi Seteyeobot. "A proposed solution to the determination of water saturation: using a modelled equation." Journal of Petroleum Exploration and Production Technology 8, no. 4 (2018): 1009-1015. https://doi.org/10.1007/s13202-018-0453-4

[20] Ibrahim, Dogan. "An overview of soft computing." Procedia Computer Science 102 (2016): 34-38. https://doi.org/10.1016/i.procs.2016.09.366

[21] Thampi, Sabu M., and El-Sayed M. El-Alfy. "Soft computing and intelligent systems: techniques and applications." Journal of Intelligent \& Fuzzy Systems 36, no. 3 (2019): 1939-1944. https://doi.org/10.3233/JIFS-169905

[22] Potey, Madhuri, and Pradeep K. Sinha. "Review And Analysis Of Machine Learning And Soft Computing Approaches For User Modeling." International Journal of Web \& Semantic Technology 6, no. 1 (2015): 39-55. https://doi.org/10.5121/ijwest.2015.6104

[23] Zen, Hidayah Nurul Hasanah, Laila Wahyu Trimartanti, Zaenal Abidin, and Agus Maman Abadi. "Determining hydrocarbon prospective zone using the combination of qualitative analysis and fuzzy logic method." Journal of Systems Science and Systems Engineering 26, no. 4 (2017): 463-474.

https://doi.org/10.1007/s11518-017-5348-2

[24] Noor, Ilanur Muhaini Mohd, and Muhamad Kamal Mohammed Amin. "Optimized Parameters of Wastewater Treatment System Using Fuzzy Control." Journal of Advanced Research in Applied Sciences and Engineering Technology 5, no. 2 (2016): 27-35.

[25] Matar, Sami, and Lewis F. Hatch. Ilmu Kimia: Proses Petrokimia Edisi Ke-2. Gulf Publishing Company, 2000.

[26] Crain, E. R. Crain's Petrophysical Handbook. CPH, 2015. https://spec2000.net.

[27] Takagi, Tomohiro, and Michio Sugeno. "Fuzzy identification of systems and its applications to modeling and control." IEEE Transactions On Systems, Man, and Cybernetics 1 (1985): 116-132.

https://doi.org/10.1109/TSMC.1985.6313399

[28] Sugeno, Michio, and Takahiro Yasukawa. "A fuzzy-logic-based approach to qualitative modeling." IEEE Transactions on Fuzzy Systems 1, no. 1 (1993): 7-31.

https://doi.org/10.1109/TFUZZ.1993.390281

[29] Suganya, R., and R. Shanthi. "Fuzzy c-means algorithm-a review." International Journal of Scientific and Research Publications 2, no. 11 (2012): 1-3.

[30] De Myttenaere, Arnaud, Boris Golden, Bénédicte Le Grand, and Fabrice Rossi. "Mean absolute percentage error for regression models." Neurocomputing 192 (2016): 38-48. https://doi.org/10.1016/i.neucom.2015.12.114

[31] Užga-Rebrovs, Oḷegs, and Gaḷina Kuḷešova. "Comparative analysis of fuzzy set defuzzification methods in the context of ecological risk assessment." Information Technology and Management Science 20, no. 1 (2017): 25-29. https://doi.org/10.1515/itms-2017-0004 
[32] Wang, Li-Xin. A Course in Fuzzy System and Control. Prentice Hall PTR, 1997. 